\title{
Implantação de frota própria para transporte na indústria de rações: um estudo de viabilidade
}

\author{
Douglas Rayzer ${ }^{1}$ \\ Niloar Bissan ${ }^{2}$ \\ Rodrigo André Fernandes ${ }^{3}$ \\ Cesar Augustus Winck ${ }^{4}$
}

\begin{abstract}
RESUMO
O objetivo deste artigo foi estudar a viabilidade de implantação de frota própria de caminhões para o transporte de rações, por uma agroindústria no Oeste de Santa Catarina. O método utilizado na pesquisa foi indutivo, permitindo investigação com base em dados numéricos, que demonstraram a realidade do lócus de estudo. Foram verificados os custos incorridos da implantação de uma frota própria na empresa, os investimentos, custos fixos e variáveis. A partir destes dados foi realizada a análise de viabilidade de investimento através de métodos de avaliação de projetos. Concluiu-se que com a aquisição da frota, ocorreriam melhorias nos serviços de entregas de rações aos clientes, em vista de que os caminhões e os motoristas seriam treinados pela empresa, prestando um serviço personalizado, porém não existiria um retorno do investimento de forma rápida e com a taxa de aplicação baseada na empresa, sendo assim seria inviável a aquisição de uma frota própria.
\end{abstract}

Palavras-chave: Logística. Terceirização. Agronegócio.

\section{Implantation of own fleet for transportation in the feed industry: a feasibility study}

\begin{abstract}
The purpose of this research was to study the feasibility of implementing an own fleet of trucks for the transport of feed, by an agroindustry, located in the west region of Santa Catarina state, Brazil. The method used in the research was inductive, allowing investigation based on numerical data, which demonstrated the reality of the study locus. The costs of deploying its own fleet in the company have been analyzed, like the investments, fixed and variable costs. From these data was performed an analysis through project evaluation methods to investment feasibility. It was concluded that with the acquisition of the fleet, there would be improvements in the supply of feed services to customers, in view of the trucks and the drivers would be trained by the company, providing personal service. However, there would be no quickly return of the investments and with the application rate based on the company, it would be impracticable to purchase a fleet of its own.
\end{abstract}

Keywords: Incubator; Agribusiness; Startup; Technology; University.

\section{INTRODUÇÃO}

O modal rodoviário é ainda, em níveis nacional e global, o maior responsável pelo transporte de cargas, tanto em volume quanto em valores, assumindo assim grande importância na economia mundial. Mais especificamente no Brasil, o grande número de

\footnotetext{
${ }^{1}$ Acadêmico do programa de Mestrado em Administração Profissional - UNOESC Chapecó. Endereço: Rua Frei Rogério, 869 - Centro - Campos Novos/SC - CEP: 89620-000. E-mail: douglasrayzer@ hotmail.com

${ }^{2}$ Acadêmico do programa de Mestrado em Administração Profissional - UNOESC Chapecó.

${ }^{3}$ Acadêmico do programa de Mestrado em Administração Profissional - UNOESC Chapecó.

4 Professor do programa de Mestrado em Administração Profissional - UNOESC Chapecó. Dr. em Agronegócios. Endereço: Av. Nereu Ramos,3777-D - Seminário - Chapecó/SC - CEP 89813-000.
} 
transportadores de cargas, sejam empresas ou transportadores autônomos, oferecem maior poder de escolha ao cliente em contratar um prestador deste tipo de serviço para transportar seu produto (BALLOU, 2011).

A logística está inserida e analisada no processo de processamento dos pedidos, distribuição dos produtos, estoques e armazenagens e em todo o processo da cadeia de suprimentos, focando nos conceitos de transporte bem como nas melhores alternativas de distribuição através das necessidades dos clientes e disponibilidade de recursos da empresa, procurando a satisfação do cliente com melhor custo-benefício possível. A logística busca contribuir para que a empresa fidelize seus clientes e os atenda de maneira a atingir suas expectativas (BOWERSOX e CLOSS, 2011).

Considerando que o cliente é o fator mais importante para as empresas e sua satisfação é o objetivo em que toda empresa deseja atingir verifica-se que as entregas através de um serviço personalizado é um dos fatores que aumentam sua satisfação. As empresas colocam na responsabilidade de terceiros chamados transportadores a finalização de seus processos, a entrega, é o último contato com o cliente o ponto chave em alguns casos para novas negociações, através deste ponto chave nota-se que a frota própria para a empresa é um diferencial de mercado. O presente estudo justifica-se pelas expectativas das indústrias de rações em atender ao cliente com um serviço especializado de entrega e com a análise de viabilidade econômica e retorno do investimento que a empresa pretende realizar.

Para o desenvolvimento deste estudo, tomou-se por objeto uma empresa de produção de ração para nutrição animal, localizada na Região Oeste de Santa Catarina. A empresa produz rações para a produção de aves, bovinos e suínos que abastecem propriedades de terminação de animais no local por meio de frota terceirizada de caminhões.

Como forma de potencializar os custos da empresa, definiu-se como objetivo geral deste estudo analisar a viabilidade de implantação de frota própria para a distribuição de ração ao produtor rural. Para atender a este objetivo, será abordada a logística das empresas, focando na área de transporte através do enfoque das distribuições e entregas através das frotas próprias de caminhões e serviço de entrega terceirizado.

\section{REFERENCIAL TEÓRICO}

As organizações optam por desenvolver suas atividades com estoques reduzidos, tornando-se necessário um serviço de transporte mais rápido para atender a esse tipo de 
demanda. Assim, o conceito de transporte de produtos para atender o cliente passa a ter uma visão mais ampla, entendido como um processo que envolve o fluxo da cadeia de suprimentos por meio do planejamento, implementação e controla do fluxo e estocagem de bens, serviços e informações que envolvem desde a origem até o consumo, com objetivo de atender as necessidades dos clientes (CAIXETA-FILHO; MARTINS, 2001).

Esta percepção passa a compor um campo de estudos denominado de logística. Campo este, primordial a todos os departamentos de uma organização e que tem grande influência sobre o atendimento de clientes, tomada de decisões, custos e sucesso da empresa, por envolver desde o sistema de processamento dos pedidos, distribuição dos produtos, estoques, armazenagens, ou seja, todo o processo da cadeias (GURGEL, 2000; BALLOU, 2011).

Neste tópico foram abordados os conceitos de transporte rodoviário de cargas, logística e análises financeiras, como forma de fundamentar a proposição da análise de viabilidade deste estudo.

\subsection{LOGÍSTICA}

A logística é entendida como uma área que engloba desde o início do atendimento ao cliente através dos departamentos de vendas, planejamento de materiais, planejamento e controle da produção, distribuição, expedição até a entrega e que tem por objetivo atender os clientes com o produto certo, no momento certo e quantidade certa. Esta consideração vem ao encontro do exposto por Gurgel (2000, p. 260), em que o autor cita que "É necessário atender as necessidades dos consumidores em prazo muito curto. Devemos colocar as mercadorias no lugar certo, na hora certa, qualidade certa e quantidades certas, pois qualquer falha de abastecimento resultará em perdas de vendas".

A logística é diretamente responsável pela satisfação do cliente e possibilita a redução de custos em toda a cadeia integrada, pois, os departamentos integrados proporcionam um melhor desempenho das atividades, como por exemplo, se o departamento de vendas e distribuição estiver interligado a entrega ao cliente será eficaz e o cliente irá detectar através da entrega as vantagens de se trabalhar com a empresa (CAIXETA-FILHO; MARTINS, 2001).

$\mathrm{Na}$ cadeia de abastecimento logística são delineadas as atividades de maior relevância e as atividades de suporte ou apoio. As atividades primárias são aquelas que têm 
maiores impactos com custos que são: transportes, manutenção dos estoques e processamento de pedidos (BALLOU, 2011).

Basicamente a logística atua na função inicial desde o fornecedor passando pela empresa para armazenagem ou processo de fabricação e entrega do produto final com diferenciais como planejamento e controle dos processos buscando facilitar os fluxos internos e externos da empresa, colocando os produtos no momento em que o cliente necessita atingindo a satisfação dos clientes com melhor custo (BALLOU, 2011).

\subsection{FUNCIONALIDADE E PRINCÍPIOS DO TRANSPORTE}

O setor de transporte por suas funcionalidades e desempenho perante a cadeia de distribuição e atendimento aos clientes é um dos elementos fundamentais da área logística. De acordo com Bowersox e Closs (2011, p. 279), “[...] a distribuição é o ato de programar os embarques e expedições da cadeia logística, enquanto o transporte e a distribuição trabalham juntos, sendo que a distribuição programa o transporte e o transporte apresentam cenários à distribuição".

Ballou (2011) considera que a necessidade de transporte é visível em todas as movimentações de produtos, como matérias primas, produtos em transformações e entregas ao cliente final. Corroborando com esta ideia Bowersox e Closs (2011) relatam que o transporte tem como objetivo movimentar produtos de uma origem até um destino definido, reduzindo, de forma equitativa, os custos financeiros, temporais e ambientais. Ao mesmo tempo, a movimentação deve atender às expectativas dos clientes em relação a performance das entregas e à disponibilidade de informações relativas às cargas transportadas.

O transporte é o maior custo da cadeia logística e podem ser subdivididos em transporte da logística de abastecimento, que é o transporte de matérias primas e o transporte de distribuição, que são os produtos acabados ou matérias primas de revenda para seus clientes. Conforme Gurgel (2000, p. 396): “[...] Logística de abastecimento: devido à necessidade de se incluir o valor do frete no custo das matérias-primas, podem-se reduzir os custos por meio de boa administração dos transportes de matérias-primas". Partindo deste pressuposto, além do abastecimento é essencial a distribuição os seus clientes que por sua vez também existem custos para a empresa, sendo ela: "Logística de distribuição: os serviços prestados ao cliente resultam em despesas de transporte, que oneram as despesas comerciais" (GURGEL, 2000, p. 396). 
Segundo Ballou (2011, p.24) "a administração da atividade de transporte geralmente envolve decidir-se quanto ao método de transporte, aos roteiros e à utilização da capacidade dos veículos”. Ainda conforme o autor, “[...] é necessário consolidar o máximo possível a carga para que a empresa obtenha ganho em volume de ocupação e melhoria no custo de frete.

Bowesox e Closs (2011) dizem que os recursos financeiros que são utilizados pelo transporte são necessários para contratação de um dos modais para envio de produtos. No Brasil o modal mais utilizado no transporte é o rodoviário que demanda de um custo financeiro elevado na contratação de transportadores ou frota própria.

As programações de veículos são realizadas por meio da identificação do volume de pedidos para envio aos clientes. Esta programação é fundamental tanto para o atendimento interno, envolvendo aspectos como horários agendados para expedição não impactando no tempo de permanência do veículo na empresa, quanto para o atendimento externo, programando as atividades conforme necessidade do cliente, para que o produto seja entregue no momento correto e atendendo sua satisfação (BOWERSOX; CLOSS, 2011).

Os custos de transporte são entendidos como gastos realizados na movimentação do produto desde a origem até ao destino e irão compor o preço final do produto. De acordo com Ballou (2011), vários fatores influenciam os custos de transporte, como a densidade do produto e a facilidade do seu manuseio, o modal de transporte e localização do cliente.

Esta condição pode ser justificada com base em Hijjar (2008) que argumenta com exemplos de rotas com origem no estado de São Paulo, que normalmente são mais caras que rotas destinadas a este estado. O valor pago por movimentações de cargas do estado do Rio de Janeiro para São Paulo é 34\% mais baixo do que na rota inversa. O valor médio do frete rodoviário de uma carreta fechada transportando carga seca é de R\$137/mil ton./km na direção São Paulo-Rio de Janeiro, contra R \$ 91/mil ton./km na direção contrária. Esta mesma ocorrência acontece em rotas com perfil semelhante entre os estados de São Paulo, Minas Gerais e Paraná.

Keedi (2011) considera que os elementos que são levados em consideração na formação do custo do transporte são: os preços dos combustíveis, despesas com o veículo, seguro de cargas, impostos e recursos humanos. Caixeta-Filho (2001) complementa ao citar como fatores determinantes do frete a distância que o veículo percorre, custos operacionais, taxas de carregamento e descarga, padrões de carga ou exigências dos clientes, aspectos geográficos, vias utilizadas e prazos de entregas. E ainda, que o contratante do transporte sempre paga por estes custos mesmo que as vezes indiretamente devido um acerto de valores. 


\subsubsection{Transporte Terceirizado Versus Transporte Próprio}

O transporte terceirizado difere-se do transporte de frota própria, pois os serviços são contratados e a entrega fica condicionada a um terceiro, ou seja, a entrega da empresa enquanto aos clientes fica sob a responsabilidade da chamada transportadora (BOWERSOX; CLOSS 2011).

Para Bowersox e Closs (2011, p. 281): “A transportadora como intermediaria, tem uma perspectiva um pouco diferente. Ela tem como objetivo aumentar sua receita bruta mediante a transação, ao mesmo tempo, minimizando os custos necessários para concluir a transação."

Ballou (2011, p. 139) expõe que “A administração da função de transporte contratado de terceiros é diferente da movimentação realizada por frota própria. Para serviços contratados, a negociação de fretes, a documentação, a auditoria e a consolidação de fretes são assuntos relevantes", considerando-se assim a negociação dos fretes como algo complexo e que utiliza tempo do profissional do transporte.

Caixeta-Filho (2001, p. 89) considera ainda que "A oferta do serviço é organizada, por transportadores em circulação regular, ou contratados especialmente para determinada viagem, por frota própria, por prestadores de serviço e por agenciadores, entre os vários modais possíveis."

Já o transporte por meio de frota própria é um fator utilizado principalmente para melhorar o atendimento aos clientes, através de um melhor desempenho nas entregas, porém para que isso ocorra é necessário que a empresa realize um investimento em equipamentos (caminhões), um investimento que atende muitos requisitos específicos dos clientes e assumindo alguns riscos como o de retorno do investimento (BALLOU, 2011).

A frota própria proporciona a empresa maior confiabilidade com seus clientes e atendimento, pois o caminhão é da empresa e a entrega ira seguir seus padrões de atendimento ao cliente. Ballou (2011, p. 143) considera que a vantagem da frota própria está em “[...] ]obter custos menores e melhor desempenho na entrega do que seria possível através do uso de transportadores convencionais".

\subsection{ANÁLISE FINANCEIRA}

A análise financeira tem como objetivo auxiliar na tomada de decisões, bem como auxiliar nas alternativas financeiras da empresa através de investimentos e avaliação dos 
melhores projetos apresentando possíveis cenários do futuro da empresa. De acordo com Assaf Neto (2012) as deliberações financeiras são tomadas pelas organizações de forma constante e assertiva. A decisão do emprego dos recursos financeiros, considerado como o mais significativo de todos, envolve todo o procedimento de identificação, avaliação e seleção das possibilidades de aplicação de recursos na perspectiva de se obter benefícios econômicos futuros.

Por meio das análises financeiras é possível definir o investimento a fazer, realizar seu acompanhamento e verificar o retorno do investimento ao decorrer dos períodos que podem ser definidos por meses ou anos (LEMES JUNIOR; RIGO; CHEROBIM, 2002). Estas análises serão determinantes para a tomada de decisão do investimento, sendo necessários alguns indicadores e relatórios gerenciais, como a projeção de fluxos de caixas, analisando as entradas e saídas, tendo ainda a inclusão de índices como inflações, taxas de financiamentos ou taxas de aplicações financeiras (ASSAF NETO, 2012).

Para desenvolvimento deste estudo, utilizou-se para análise de viabilidade o fluxo de caixa, payback, Taxa Interna de Retorno - TIR e Valor Presente Líquido - VPL, definidos por diversos autores conforme o Quadro 1.

Quadro 1 - Definição de indicadores de viabilidade

\begin{tabular}{|l|l|l|}
\hline \multicolumn{1}{|c|}{ Indicador } & \multicolumn{1}{c|}{ Autor } & \multicolumn{1}{c|}{ Conceito } \\
\hline Fluxo de caixa & ZDANOWICZ, 2004 & $\begin{array}{l}\text { Visualização das atividades desenvolvidas, } \\
\text { bem como as operações financeiras que são } \\
\text { realizadas diariamente, no grupo do ativo } \\
\text { circulante, dentro das disponibilidades, e que } \\
\text { representam o grau de liquidez da empresa. }\end{array}$ \\
\hline Payback & ASSAF NETO, 2012 & $\begin{array}{l}\text { Consiste na determinação do tempo } \\
\text { necessário para que o dispêndio de capital } \\
\text { (valor de investimento) seja recuperado por } \\
\text { meio dos benefícios incrementais líquidos de } \\
\text { caixa (fluxo de caixa) promovidos pelo } \\
\text { investimento. }\end{array}$ \\
\hline $\begin{array}{l}\text { TIR - Taxa Interna De } \\
\text { Retorno }\end{array}$ & LEITE, 2004 & $\begin{array}{l}\text { Taxa de lucratividade esperada dos projetos } \\
\text { de investimento, para obtermos essa taxa } \\
\text { pode-se partir de dois elementos } \\
\text { fundamentais: o preço de oferta do bem de } \\
\text { capital e as entradas previstas que serão } \\
\text { proporcionadas pela operação deste ativo } \\
\text { fluxo de caixa = lucro operacional + } \\
\text { depreciação). }\end{array}$ \\
\hline VPL-Valor Presente & ASSAF NETO, 2012 & $\begin{array}{l}\text { Este método procura avaliar o valor presente } \\
\text { líquido através dos fluxos de caixa } \\
\text { verificando assim os períodos de duração da } \\
\text { análise do investimento. }\end{array}$ \\
\hline Líquido & & \\
\hline
\end{tabular}

Fonte: Baseado em Zdanowicz (2004); Assaf Neto 92012); Leite (2004). 
Os indicadores listados no Quadro 1 foram calculados para o desenvolvimento deste estudo, segundo o investimento realizado. Lemes et al (2002, p. 9) cita: "Entende-se por investimento toda a aplicação de capital em algum ativo tangível ou não, para obter determinado retorno no futuro. Um investimento pode ser a criação de uma nova empresa ou pode ser um projeto em uma empresa já existente, por exemplo".

Para atender o objetivo proposto por este estudo, utilizou-se inicialmente da pesquisa exploratória, como forma de proporcionar uma visão geral e aproximada do estudo, tornandoo mais preciso. A pesquisa exploratória segundo Marconi e Lakatos (2012, p. 71): “[...] são investigações de pesquisa empírica cujo objetivo é a formulação de questões ou de um problema $[\ldots] "$.

A aplicabilidade da pesquisa exploratória para desenvolvimento deste estudo é justificada também com base em Gil (2008, p. 27), em que autor considera que "As pesquisas exploratórias têm como principal finalidade desenvolver, esclarecer e modificar conceitos e ideias, tendo em vista a formulação de problemas mais precisos ou hipóteses pesquisáveis para estudos posteriores".

Para análise de viabilidade proposta, os dados a seguir foram buscados através do que determinam Marconi e Lakatos (2012), desenvolvendo o estudo em fases compostas por pesquisas bibliográficas sobre o estudo, para em seguida desenvolver um modelo de teorias e referenciais passando assim a determinar a coleta dos dados e para finalizar antes da realização da coleta de dados primários, verificarem quais análises serão utilizadas com os dados.

Os dados primários foram coletados por meio de entrevistas e análise de documentos gerenciais da empresa objeto de estudo. As entrevistas são definidas por Gil (2008) como uma "[...] técnica em que o investigador se apresenta frente ao investigado e lhe formula perguntas, com o objetivo de obtenção dos dados que interessam a investigação". Os dados foram coletados com a área logística da empresa, com base em seu último ano físcal (2015), observando-se as rotas de entregas, a população e a quantidade de caminhões necessários para realizar as entregas da empresa.

\section{RESULTADOS E DISCUSSÃO}

As indústrias de rações trabalham com métodos internacionais de qualidade e boas práticas de fabricação, para alcançar seus objetivos e certificações, bem como o crescimento e 
satisfação de seus clientes. Para tanto a empresa propõe estratégias a longo prazo, buscando o atendimento diferenciado com valor agregado em seus produtos e serviços.

A partir destas estratégias e da necessidade de melhorias contínuas, foi realizado este estudo sobre o atendimento de seus clientes com frota própria na empresa, um serviço de entrega com motoristas internos, treinados e alinhados com os objetivos da empresa, e com equipamentos (caminhões) novos mostrando aos seus clientes um diferencial e melhor aparência em suas entregas.

$\mathrm{Na}$ atualidade as entregas são realizadas por transportadoras terceirizadas, atendendo o cliente por meio de intermediários que recebem treinamento. Porém são identificadas falhas nas entregas, ocorrem em $50 \%$ por falta de produto, em que a transportadora entregou ao cliente faltando produto, $20 \%$ em virtude de avarias durante o transporte como: produto molhado, sacaria rasgada ou suja, entre outros, $10 \%$ sendo por inversão de entrega que ocorre por falta de atenção durante a entrega aos clientes e outros em que ocorrem casos de paletes tombados ao chegar no cliente, transportadora não atendeu exigência particular do cliente entre outros. No caso de falhas ou erros aciona-se a transportadora apontando o ocorrido, porém o critério de mitigação dos riscos é baixo, comparando com uma frota própria em que se tem ação imediata sobre os motoristas.

Para evidenciar a importância da frota própria para as indústrias realizou-se uma entrevista com os coordenadores dos transportes da empresa objeto de estudo e com colaboradores de atendimento ao cliente e distribuição. Com base nos depoimentos, elencaram-se os seguintes pontos que se pretende aperfeiçoar com a implantação da frota própria: serviço diferenciado de entrega; atendimento personalizado, com motoristas e caminhões próprios; redução nas falhas nas entregas; maior comprometimento do motorista nas entregas e maior flexibilidade de tomada de ação em relação aos motoristas; maior facilidade de controle e implantação e sistemas de controle e rastreamento dos caminhões para acompanhamento das entregas; comunicação eficiente entre transportes e atendimento ao cliente com os motoristas identificando com facilidade exigências dos clientes; clientes mais satisfeitos.

Após verificar os pontos de importância da implantação da frota própria na visão dos departamentos internos, foram realizados levantamentos documentais da situação atual das entregas da empresa e a análise de viabilidade para implantação deste projeto. 
O transporte de mercadorias até a entrega é realizado por meio do modal rodoviário de cargas com caminhões que carregam até 30 toneladas, sendo eles caminhões tocos, caminhões com capacidade de carregamento de 8 toneladas, trucks caminhões com capacidade de carga em 14 toneladas e carretas com capacidades que variam de 26 a 30 toneladas.

Com os dados observados por meio de documentos como planilhas de controle e relatórios gerenciais, foi possível identificar que os caminhões trucks são os de maior representatividade no envio das cargas. Com base no volume de cargas e entregas foi realizada uma pesquisa documental levantando dados internos da empresa, como o volume de entregas do último ano e constatou-se a necessidade de aquisição dos caminhões para realização das entregas, quantificando a necessidade de compra de 12 caminhões para aquisição da frota, que demandam também a contratação de 12 motoristas.

Em comparação com a representatividade dos caminhões, os trucks que representam em utilização $69,20 \%$ poderão ser comprados com representatividade na compra de 8 caminhões sendo 66,67\%. Os caminhões tipo "toco" que representa 14,22\% em utilização e na compra de 2 caminhões representou $16,66 \%$ e as carretas que sua representatividade é de $16,58 \%$ na compra de 2 carretas representando $16,66 \%$, percebe-se então que a compra está adequada com a real necessidade de atendimento da empresa.

Com base no levantamento da quantidade dos caminhões necessários para atendimento da frota própria, foram realizados orçamentos em concessionárias de veículos, sendo feita a opção pela melhor proposta comercial para aquisição de caminhões novos (zero quilometro), apresentando também as garantias de fábricas que os caminhões possuem para motor e peças. Quantificaram-se ainda necessidades para aquisição de equipamentos, como carrocerias e equipamentos de distribuição, totalizando $\mathrm{R} \$ 3.191 .000,00$ conforme exposto na Tabela 1.

Tabela 1 - Valor total dos investimentos iniciais.

\begin{tabular}{lccccr}
\hline \multicolumn{1}{c}{ Tipo } & Un. & Caminhões R\$ & $\begin{array}{c}\text { Carrocerias } \\
\mathbf{R} \$\end{array}$ & $\begin{array}{c}\text { Semi reboque } \\
\text { R\$ }\end{array}$ & $\begin{array}{c}\text { Valor Total } \\
\mathbf{R} \$\end{array}$ \\
\hline Toco & 2 & $185.000,00$ & $14.500,00$ & - & $399.000,00$ \\
Truck & 8 & $230.000,00$ & $17.500,00$ & - & $1.980 .000,00$ \\
Cavalo da Carreta & 1 & $325.000,00$ & - & $72.000,00$ & $397.000,00$ \\
Cavalo da Carreta LS & 1 & $325.000,00$ & - & $90.000,00$ & $415.000,00$ \\
Valor total para aquisição dos caminhões & & & $\mathbf{3 . 1 9 1 . 0 0 0 , 0 0}$ \\
\hline
\end{tabular}

Fonte: Os autores 
Para realização das entregas com frota própria foi preciso realizar um levantamento de custos fixos em função da alteração no formato de entregas. Os custos fixos são pagos independentemente da utilização do bem, no caso da frota própria são: licenciamento anual dos caminhões, manutenções/revisões preventivas no caminhão, rastreador dos caminhões, seguro do caminhão, salário dos motoristas e encargos.

Na Tabela 2 são apresentados os valores totais dos custos fixos que irão incorrer na empresa com a aquisição de frota própria.

Tabela 2 - Custos fixos

\begin{tabular}{lr}
\hline Descrição & Valor Total \\
\hline Valor Total do Licenciamento Anual dos caminhões & $\mathrm{R} \$ 31.430,00$ \\
\hline Valor Total de manutenções preventivas & $\mathrm{R} \$ 37.827,52$ \\
\hline Valor total de rastreador anual & $\mathrm{R} \$ 20.160,00$ \\
\hline Valor de seguro total dos caminhões anual & $\mathrm{R} \$ 190.000,00$ \\
\hline Total de Custo Anual com funcionários & $\mathrm{R} \$ 529.578,12$ \\
\hline Custo fixo Total & $\mathbf{R} \mathbf{8 0 8 . 9 9 5 , 6 4}$ \\
\hline
\end{tabular}

Fonte: Os autores

Os custos variáveis ocorrem em virtude de vários aspectos, o principal é o volume e distância percorrida pelos caminhões. Nestes custos são calculados o combustível e arla $32^{5}$ que são custos que dependem de uma rotatividade do veículo para consumo, neste caso a quilometragem em que o veículo percorre. Outro custo variável são as horas extras do motorista e custos com lavagens dos caminhões. Os custos variáveis foram quantificados em $\mathrm{R} \$ 359.182,63$ anual.

Para realização da análise de viabilidade, foram utilizadas como entradas de caixa os custos médios de frete anual realizado na empresa, apurado em R \$ 865.294,10. Além das entradas referentes aos custos com fretes, estimou-se como entradas de caixa para análise de viabilidade coletas de retorno, apurados em $\mathrm{R} \$ 172.841,73$, totalizando $\mathrm{R} \$ 1.038 .135,83$ para este estudo.

O projeto foi analisado em um período temporal de 10 anos, tendo reajustes anuais de $11,43 \%$ anual referente a dissídios e IGPM. Estes valores compuseram o fluxo de caixa projetado, exposto na Tabela 3.

\footnotetext{
${ }^{5}$ Reagente usado para reduzir quimicamente as emissões de óxidos de nitrogênio presentes nos gases de escape dos veículos a diesel.
} 
Tabela 3 - Fluxo de caixa projetado

\begin{tabular}{|c|c|c|c|c|c|}
\hline ANO/R\$ & 2017 & 2018 & 2019 & 2020 & 2021 \\
\hline (+) Receitas & $1.156 .794,76$ & $1.289 .016,40$ & $1.436 .350,97$ & $1.600 .525,89$ & $1.783 .465,99$ \\
\hline $\begin{array}{l}\text { (-) Custos e } \\
\text { Despesas Variáveis }\end{array}$ & - 359.182,63 & - 386.266,04 & $-415.431,86$ & - 446.846,68 & - 480.690,43 \\
\hline $\begin{array}{l}\text { (-) Custos e } \\
\text { Despesas Fixas }\end{array}$ & - 808.995,64 & - 851.361,89 & - 897.117,44 & - 946.533,43 & - 999.902,71 \\
\hline (=) Saldo de caixa & - 11.383,51 & $51.388,47$ & $123.801,67$ & $207.145,77$ & $302.872,86$ \\
\hline (+/-) Investimento & - $191.000,00$ & $\mathrm{R} \$ 0,00$ & $\mathrm{R} \$ 0,00$ & $\mathrm{R} \$ 0,00$ & $\mathrm{R} \$ 0,00$ \\
\hline Fluxo de Caixa & $-202.383,51$ & - 150.995,05 & - 27.193,38 & $-820.047,61$ & $-517.174,75$ \\
\hline ANO/R\$ & 2022 & 2023 & 2014 & 2025 & 2026 \\
\hline (+) Receitas & $1.987 .316,16$ & $2.214 .466,39$ & $2.467 .579,90$ & $2.749 .624,29$ & $3.063 .906,34$ \\
\hline $\begin{array}{l}\text { (-) Custos e } \\
\text { Despesas Variáveis }\end{array}$ & $-517.157,42$ & $-556.457,50$ & $-598.817,32$ & $-644.481,67$ & $-693.714,90$ \\
\hline $\begin{array}{l}\text { (-) Custos e } \\
\text { Despesas Fixas }\end{array}$ & - 57.541,52 & - 119.791,44 & - 187.021,35 & - 259.629,66 & - 338.046,63 \\
\hline (=) Saldo de caixa & $412.617,22$ & $538.217,46$ & $681.741,23$ & $845.512,96$ & $1.032 .144,81$ \\
\hline (+/-) Investimento & 0,00 & 0,00 & 0,00 & 0,00 & 0,00 \\
\hline Fluxo de Caixa & - 104.557,53 & $-1.566 .340,07$ & $-884.598,84$ & - 39.085,88 & $993.058,93$ \\
\hline
\end{tabular}

Fonte: Os autores

Por meio da análise do fluxo de caixa projetado para o projeto, observa-se que ao final do décimo ano tem-se o valor positivo de $\mathrm{R} \$ 993.058,93$. Utilizando-se estes valores para cálculo do payback descontado a uma taxa de aplicação de $8 \%$, chega-se ao valor de R\$ 2.333.620,16 não atingindo assim o valor do investimento, apontando uma possível inviabilidade do projeto.

Ainda com base no fluxo de caixa e na taxa de aplicação de $8 \%$, estipulada pelos gestores como retorno esperado para o investimento, calculou-se o Valor Presente Líquido do investimento. Ao final de 10 anos, o VPL apurado foi de R $2.333 .620,17$, ficando abaixo do valor investido. Da mesma forma, apurou-se a Taxa Interna de Retorno do investimento, que resultou em 3,69\% no final do período, apontando assim que o investimento não remunera segundo as expectativas dos gestores da empresa.

\section{CONSIDERAÇÕES FINAIS}

A logística de transportes é um fator determinante para as empresas em vista que é uma área que envolve custos para a empresa e a finalização dos processos com cliente, as entregas. Como forma de otimizar os serviços de uma empresa produtora de ração para nutrição animal e assim reduzir reclamações de clientes e redução de custos com transportes, este estudo objetivou analisar a viabilidade de implantação de frota própria. Para alcançar o 
objetivo proposto no estudo foi realizada uma pesquisa para o levantamento de informações da situação atual da empresa do estudo na logística de distribuição atual das entregas.

Com base no referencial teórico foi possível identificar a importância da logística para as empresas, os custos que são relevantes para a realização das entregas das empresas e a percepção da diferença entre a frota terceirizada e a frota própria de entregas das empresas. Por meio de uma pesquisa documental foi identificada a expectativa dos gestores na implantação da frota própria de caminhões, que até então é feita de forma terceirizada, assumindo assim a responsabilidade em atender os clientes e reduzir custos com transportes.

No decorrer deste estudo foram realizados cálculos de investimentos e retorno, sendo observado um investimento com valor agregado alto para aquisição da frota e ao décimo ano existe um retorno de investimento, porém com a taxa de aplicação determinada através dos fatores atuais da Taxa Selic e Banco BNDES o investimento não retorna, porém, zerando estas taxas percebe-se que a TIR de retorno de $3,65 \%$ ao ano.

Conclui-se, então, que com a aquisição da frota, as melhorias nas entregas aos seus clientes ocorrem em função de que os caminhões e os motoristas são próprios da empresa e com um serviço personalizado, porém não existe um retorno do investimento de forma rápida e com a taxa de aplicação baseada na empresa, sendo assim é inviável a aquisição de uma frota própria.

Este estudo proporcionou um conhecimento amplo do significado de uma frota própria para a empresa em estudo, levando em consideração que se ponderava que a frota própria era algo simples e com grande viabilidade no atendimento aos clientes, contudo quando envolve investimentos e análises não é tão simples assim.

\section{REFERÊNCIAS}

ASSAF NETO, Alexandre. Finanças Corporativas e Valor. 6. ed. São Paulo: Atlas, 2012.

BALLOU, Ronald H. Logística Empresarial. São Paulo: Atlas, 2011.

B0WERSOX, Donald J.; CLOSS, David J.; Logística Empresarial: O processo de integração da Cadeia de Suprimento. São Paulo: Atlas, 2011.

CAIXETA-FILHO, José Vicente; MARTINS, Ricardo Silveira (Org.). Gestão Logística do Transporte de Cargas. São Paulo: Atlas, 2001. 
DOS REIS, Neuto Gonçalves. Uma formula para calcular reajustes de fretes. Disponível em: 〈http://www.guiadotrc.com.br/economia/fretecomoreajustar.asp >. Acesso em 12. set. 2016.

GIL, Antonio Carlos. Métodos e Técnicas de Pesquisa Social. 6. ed. São Paulo: Atlas, 2008.

GURGEL, Floriano do Amaral. Logística Industrial. 1. ed. São Paulo: Atlas, 2000.

HIJJAR, M. F. Preços de frete rodoviário no Brasil. Illos, 2008. Disponível em: < http://www.guiadotrc.com.br/truckinfo/Artigos/Pre\%C3\%A7os_de_Frete_Rodovi\%C3\%A1ri o.pdf >. Acesso em: 17 ago. 2016.

KEEDI, Samir. Transportes, Unitização e Seguros Internacionais de Carga. 5. ed. São Paulo: Edições Aduaneiras, 2011.

LEITE, Helio de Paula. Introdução à administração financeira. 2. ed. São Paulo: Atlas, 1994.

LEMES JUNIOR, Antônio Barbosa; RIGO, Cláudio Miessa; CHEROBIM, Ana Paula Mussi Szabo. Administração Financeira: Princípios, Fundamentos e Práticas Brasileiras Aplicações e casos nacionais. 4. ed. Rio de Janeiro: Campus, 2002.

MARCONI, Marina de Andrade; LAKATOS, Eva Maria. Técnicas de pesquisa: planejamento e execução de pesquisas; amostragens e técnicas de pesquisa; elaboração, análise e interpretação de dados. 7. ed. São Paulo: Atlas, 2012.

MINISTÉRIO DOS TRANSPORTES. Transporte Rodoviário do Brasil. Disponível em: < http://www2.transportes.gov.br/bit/02-rodo/rodo.html >. Acesso em 18 ago. 2016.

ROESCH, Sylvia Maria Azevedo. Projeto de estágio e de pesquisa em administração: Guia para Estágios, Trabalhos de Conclusão, Dissertações e Estudos de Caso. 3. ed. São Paulo: Atlas, 2006.

SEVERINO, Antônio Joaquim. Metodologia do trabalho científico. 23. ed. São Paulo: Cortez, 2007.

SOARES, Edvaldo. Metodologia Científica: Lógica, Epistemologia e Normas. São Paulo: Atlas, 2003.

VALENTE, Amir Mattar et al. Qualidade e Produtividade nos Transportes. São Paulo: Cengage Learning, 2008.

WESTON, J. Fred; BRIGHAM, Eugene F. Fundamentos da Administração Financeira. 10. ed. São Paulo: Pearson Education do Brasil, 2000.

ZDANIWICZ, José Eduardo. Fluxo de caixa: uma decisão de planejamento e controle financeiro. 10. ed. Porto Alegre: Editora Sagra Luzzatto, 2004. 